This item was submitted to Loughborough's Research Repository by the author.

Items in Figshare are protected by copyright, with all rights reserved, unless otherwise indicated.

\title{
High power RF capabilities at Loughborough University
}

PLEASE CITE THE PUBLISHED VERSION

http://ieeexplore.ieee.org/stamp/stamp.jsp?arnumber=04816081

PUBLISHER

IET / @ IEEE

VERSION

AM (Accepted Manuscript)

LICENCE

CC BY-NC-ND 4.0

REPOSITORY RECORD

Novac, Bucur M., Ivor R. Smith, and W.G. Whittow. 2019. "High Power RF Capabilities at Loughborough University". figshare. https://hdl.handle.net/2134/10028. 
This item was submitted to Loughborough's Institutional Repository (https://dspace.lboro.ac.uk/) by the author and is made available under the following Creative Commons Licence conditions.

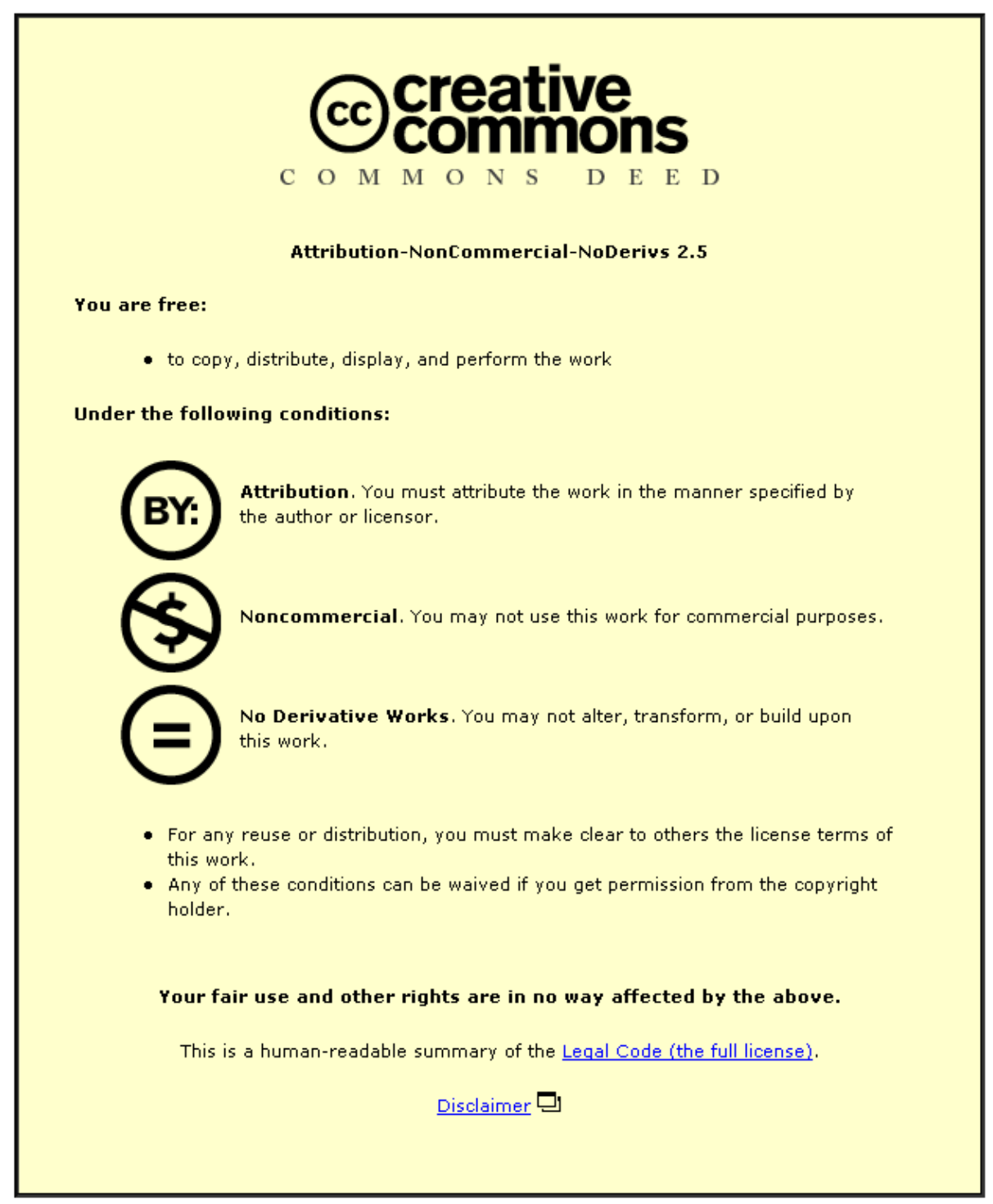

For the full text of this licence, please go to: http://creativecommons.org/licenses/by-nc-nd/2.5/ 


\title{
HIGH POWER RF CAPABILITIES AT LOUGHBOROUGH UNIVERSITY
}

\author{
B.M.Novac, I.R.Smith and W. Whittow
}

\author{
Department of Electronic and Electrical Engineering, \\ Loughborough University, Loughborough, Leicestershire LE11 3TU, UK
}

Keywords: RF, HPM, HV

\begin{abstract}
Members of the Plasma and Pulsed Power Group at Loughborough University are engaged in several experimental activities related to the generation of high power radio frequency radiation. The paper reviews some of the more important projects that have recently been successfully completed.
\end{abstract}

\section{Introduction}

Pulsed-power research at Loughborough University began some 25 years ago, with the production and measurement of blast waves from exploding wires and their use in impact studies of materials at high rates of strain. Subsequently, major facilities such as high-current capacitor banks and their ancillary equipment (ultra-high speed cameras, flash X-ray systems, digital oscilloscopes, etc) for both plasma and explosive device facilities have been introduced into what are now well equipped laboratories, with the aid of funding from the Engineering and Physical Sciences Research Council and government and industrial concerns.

During the last decade one of the areas that has been given particular attention is that of compact and repetitive power sources for high power radiation generators. Various established pulsed power techniques have been adapted for use in these applications, and a number of novel projects have been successfully completed. Of particular note is a very high repetition rate system based on an extremely compact high voltage Tesla transformer. Closely related to this has been the production of a high frequency low inductance closing switch operating under corona stabilisation. A significant technical breakthrough was achieved with the demonstration of the first magnetically insulated transformer successfully produced world wide. In an alternative development, very high power systems based on exploding wires and transformer conditioning systems have been exploited in single-shot systems to drive high power microwave generators such as Vircators and other microwave sources. Related consultancy activities have seen designs produced for both large and small explosively-driven systems for driving single shot high power microwave loads.
Blue skies research has been conducted on various novel techniques for microwave generation by unconventional means, with the most valuable result being a technique that produces ultra-wide band radiation from below 1 $\mathrm{MHz}$ up to at least $18 \mathrm{GHz}$.

\section{Compact high-voltage pulsed power sources based on Tesla transformer technology}

Due to its simplicity in design, low cost and compactness, a Tesla pulse transformer is in some cases preferred to a Marx generator, with its inherent disadvantage of a slower voltage rise-time being mitigated by use of a pulse forming line (PFL) in conjunction with a high voltage fast spark gap (FSG) switch. Two Tesla transformer based systems were developed at Loughborough in the last five years: one built for and tested in common with Dstl and operating at an output voltage in excess of $500 \mathrm{kV}$ and a much more compact unit with an output of up to $250 \mathrm{kV}$, developed for MBDA UK.

A Tesla system is in principle based on the arrangement of Fig. 1 and it can conveniently be divided into an initial energy supply, a pulsed power generator, and the radiating elements. The initial energy is usually provided by a battery pack, followed by a $30 \mathrm{kV} \mathrm{DC-DC} \mathrm{converter.}$ The pulsed power generator consists of a capacitor bank (CB) made from $2 \mathrm{nF}, 30 \mathrm{kV}$ ceramic capacitors connected in parallel to the primary winding of the aircored pulse (Tesla) transformer through a short flat transmission line, with the circuit closed through a twoelectrode pressurized air spark gap (ASG) switch. The primary winding comprising a single-turn laminated copper strip $100 \mu \mathrm{m}$ thick, sandwiched and heat bonded between two layers of Mylar-polyethylene laminate. The transformer secondary winding is usually made from a round copper conductor, wound on a conical polyethylene mandrel. A sectional view of the overall $500 \mathrm{kV}$ pulsed power generator is given in Fig. 2 and a typical output voltage waveform in Fig. 3. If required, to sharpen the voltage pulse a coaxial PFL is integrated into the secondary circuit of the transformer, together with a $\mathrm{SF}_{6}$ pressurized fast spark-gap switch (FSG). Fig. 4 shows the arrangement of the final field experiments and the radiated electric field at 


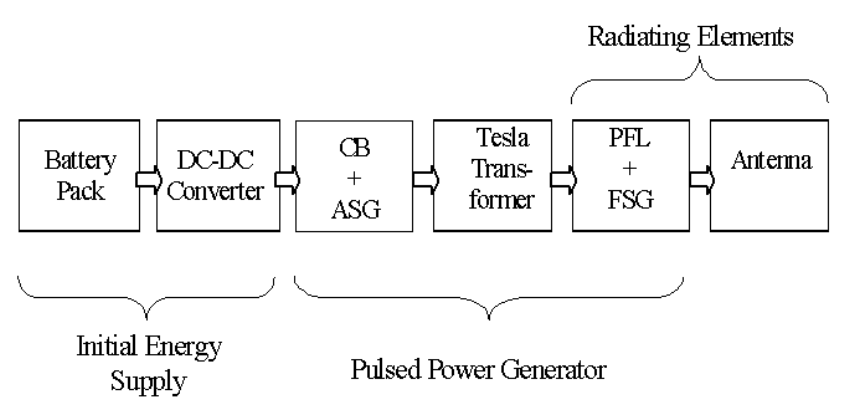

Fig. 1. Schematic of a Tesla based pulsed power generator

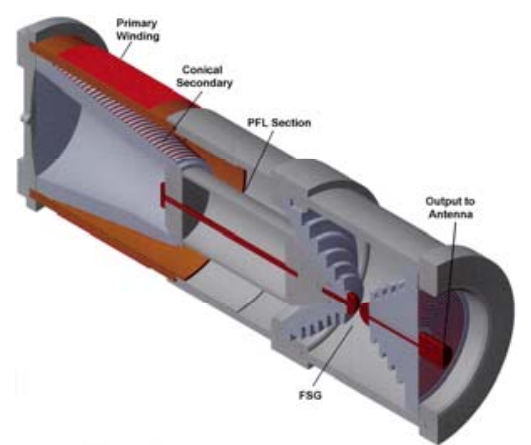

Fig. 2. Overall view of the $500 \mathrm{kV}$ pulsed power generator

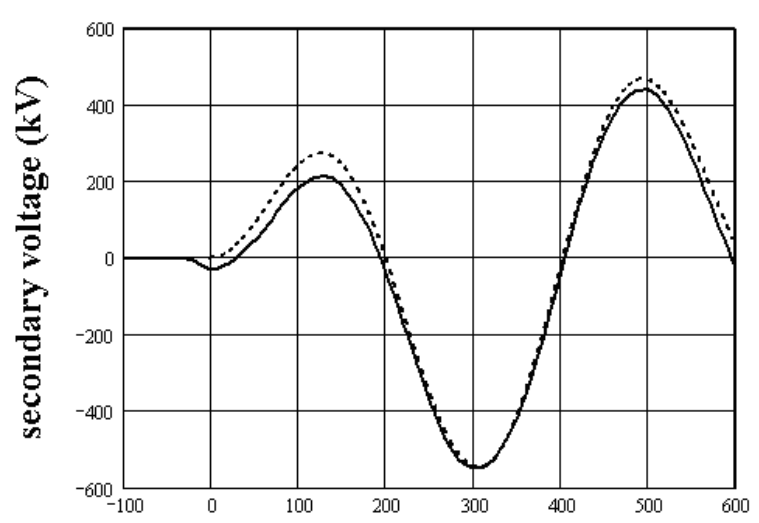

time (ns)

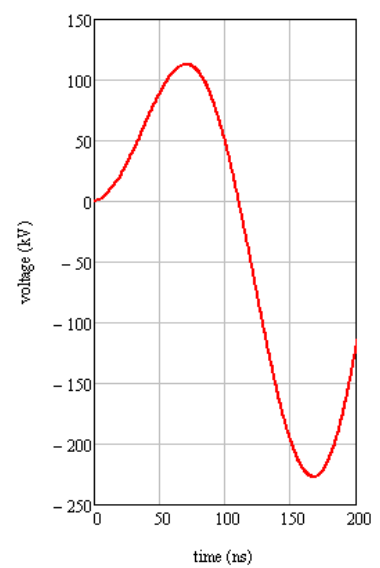

Fig. 3 Tesla transformer typical output voltage: (upper) $500 \mathrm{kV}$ unit and (lower) compact $250 \mathrm{kV}$ unit
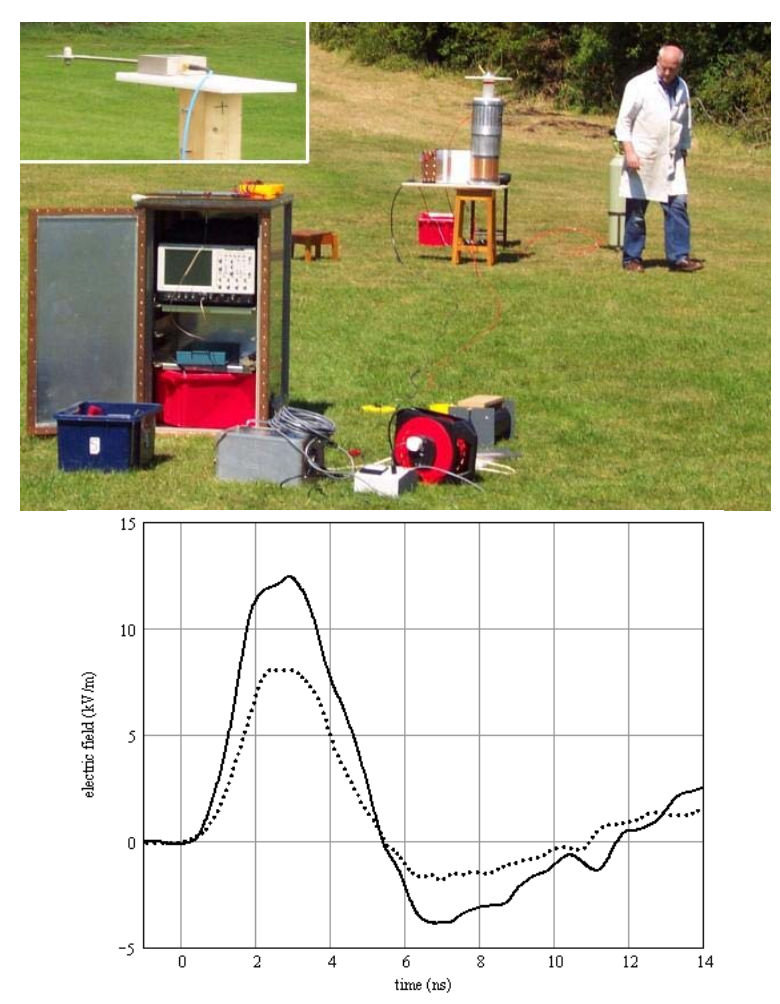

Fig. 4. (upper) Open site measurement of radiated field. Insert shows arrangement for AD-70 D-dot sensor. (lower) Radiated field waveform (after ground corrections have been applied) at $10 \mathrm{~m}$ (solid line) and $15 \mathrm{~m}$ (dotted line) from source

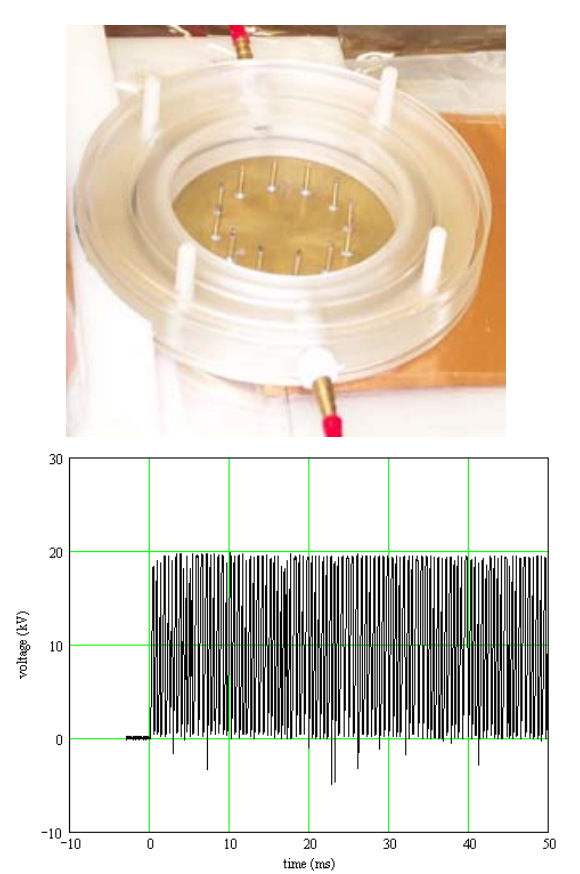

5. (upper) A view of a CS-SG;

(lower) voltage across switch at $2 \mathrm{kHz}$ PRF 

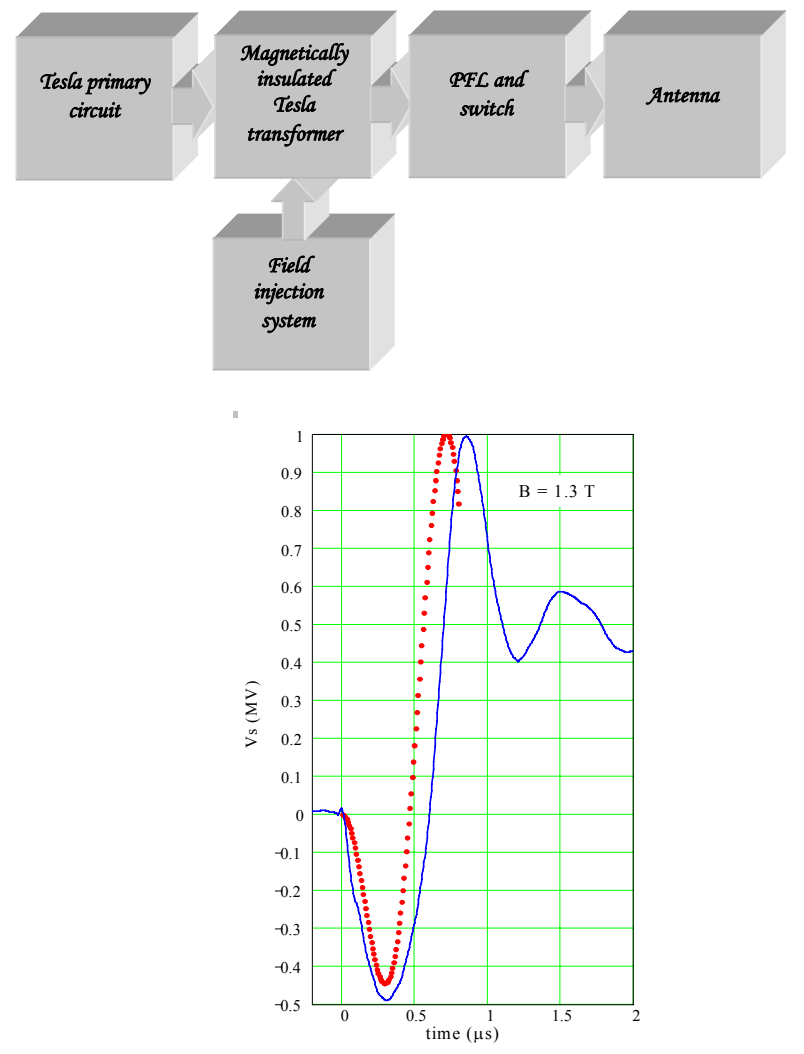

Fig. 6 (upper) Schematic of a multi-MV UWB source; (lower) $1 \mathrm{MV}$ output demonstrated
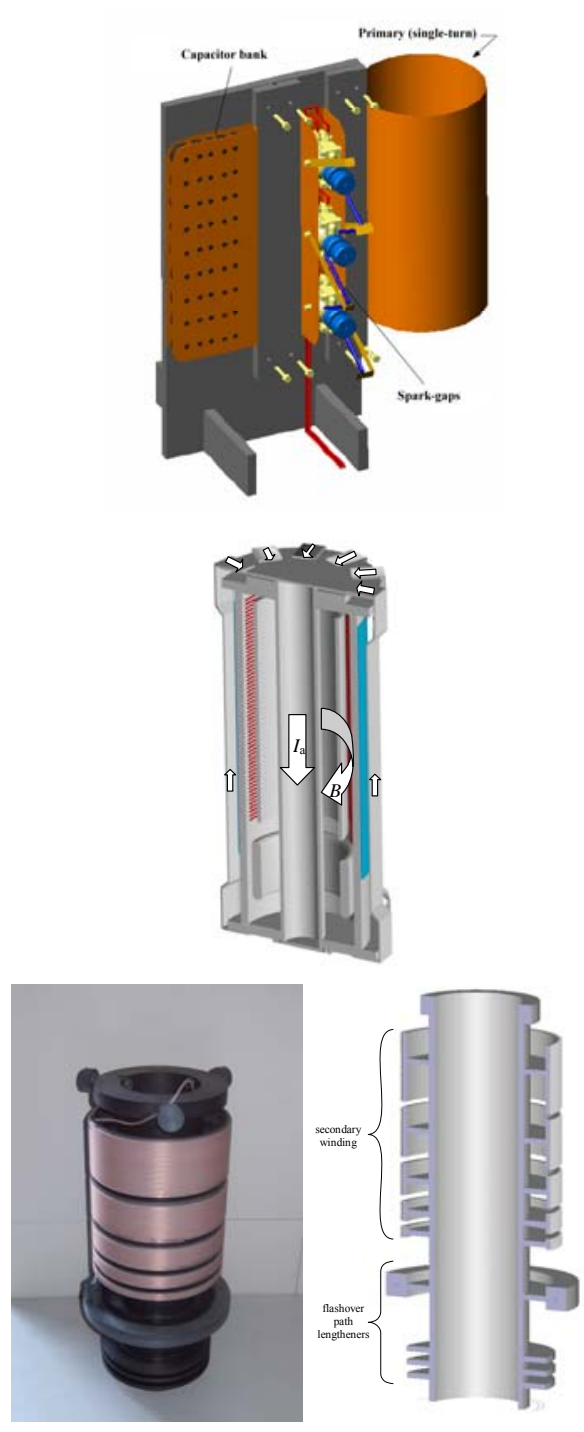

Fig. 7 (from upper to lower): primary circuit, Tesla transformer and HV secondary
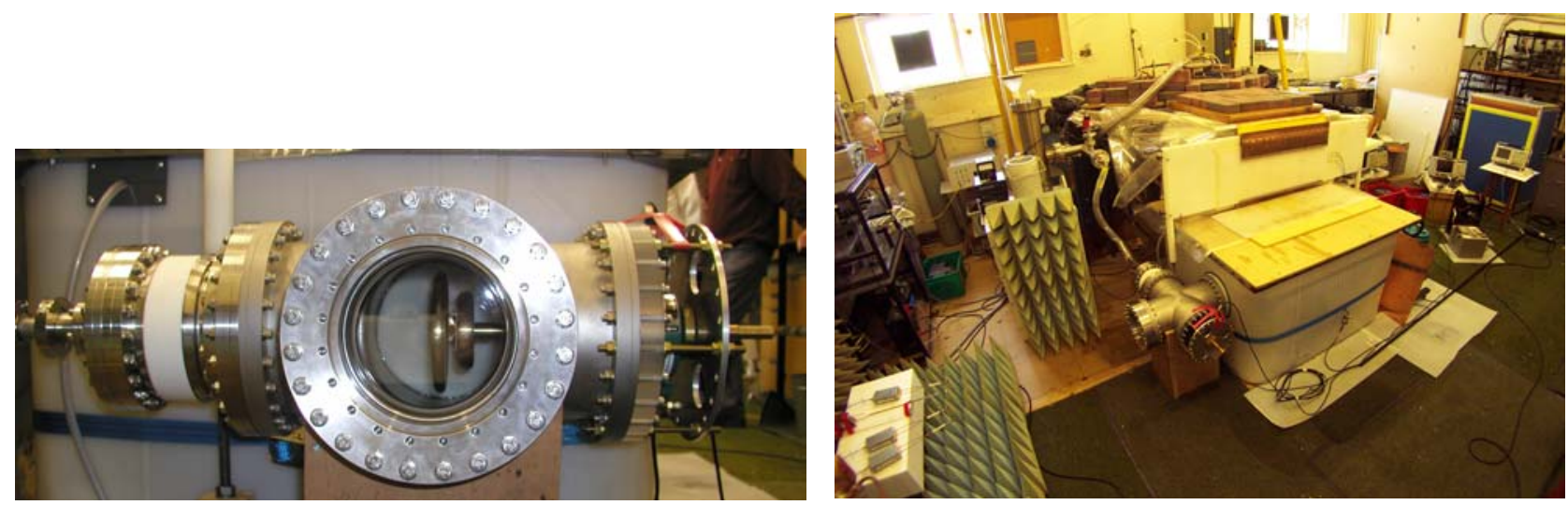

Fig. 8 (left) Vircator HPM generator; (right) overall view of complete system 

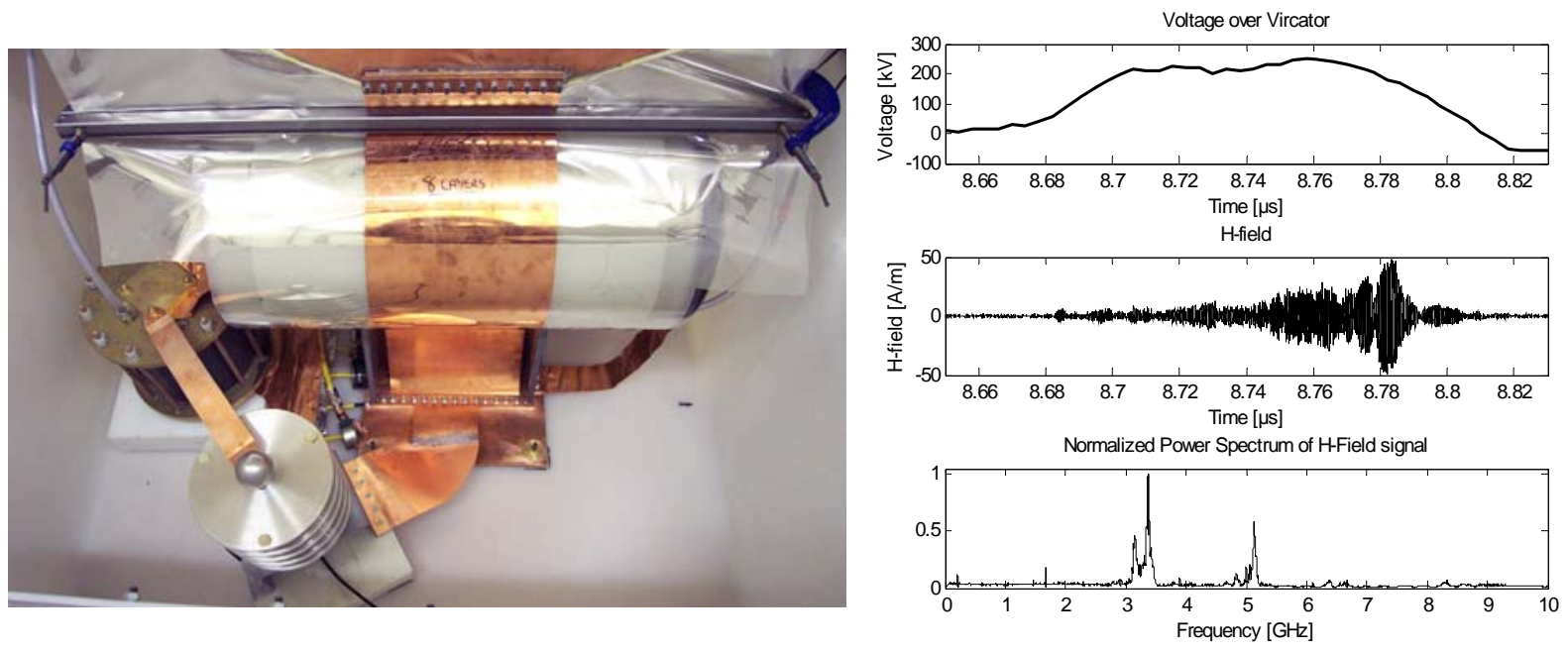

Fig. 9 (left) Arrangement inside the empty oil tank: high-voltage transformer, load and and MV probe. (right) Results from final system testing (from top to bottom): voltage pulse across vircator; microwave pulse; FFT spectrum of field signal

$10 \mathrm{~m}$ and $15 \mathrm{~m}$ after numerically removing the ground reflected wave influence from the digitally recorded data, using appropriate values for the ground conductivity and permittivity. A figure of merit (FOM) of $124 \mathrm{kV}$ is similar to or better than figures reported elsewhere for similar omni-directional EMP sources using only one-stage of pulse compression.

The trend in repetitive pulsed power is nowadays towards higher peak power and higher repetition rates. One way to increase the repetition rate by improving the recovery time of the closing switch is to use the coronastabilisation technique. This process works in the presence of both a non-uniform electric field and an electronegative gas, with a highly non-uniform field achieved by designing the electrodes of the spark-gap with a needle-plane geometry. Under these conditions, breakdown of the spark-gap is preceded by a corona discharge in the high field region. Corona encircles the highly stressed electrode and locks the field around it to a corona onset value. Breakdown of the gap will only occur when sufficient space charge is generated to increase the electric field to at least a critical value. As it takes a significant time for such a process to develop, a full voltage recovery is achieved from the overall system and any pre-fire prevented. A schematic view of such a sparkgap is shown in Fig. 5 together with results obtained when operating at a PRF of $2 \mathrm{kHz}$.

\section{Magnetically insulated transformers}

Multi-MV magnetically insulated Tesla transformer (MITT) for radiation generators can have a relatively compact design that requires only a very low-energy capacitor bank, with the intense magnetic field that is responsible for the insulation being produced via a separate coil fed from an external source allowing microsecond time scale operation. A schematic of a powerful UWB source based on this concept is given in Fig. 6, where the injected field is obtained from a pulsed power supply derived from either an auxiliary capacitor bank, as described in this paper, or a compact and autonomous source employing an explosively-driven flux compression generator.

A $1 \mathrm{MV}$ Tesla transformer operating under magnetic insulating conditions has been successfully demonstrated giving the output voltage as shown in Fig. 6, with details of the arrangement presented in Fig. 7. It is believed to be the first working magnetically insulated megavolt-size Tesla transformer.

A $1 \mathrm{MV}$ UWB source based on this technology is presently under development. Future work is planned also for a $5 \mathrm{MV}$ Tesla transformer using a FCG as an external autonomous power source for the injection field system estimated. Due to the much higher insulating field then available, around $14 \mathrm{~T}$, the transformer volume is expected to remain much the same as that of the present $1 \mathrm{MV}$ unit.

\section{Powerful but simple pulsed power generators for single-shot HPM generators}

Modern applications of high-power microwave (HPM) generators require the development of compact pulsed power supplies capable of generating a voltage pulse up to and beyond $1 \mathrm{MV}$, and of sustaining the voltage for possibly up to $1 \mu \mathrm{s}$ when a considerable microwave output is required. No simple solutions are available for this type of power source, and although megavolt Marx generators represent the most obvious answer, they are complex and have a high volume/weight ratio. An alternative is based on explosive magnetic flux compression generators (FCGs) when only a single-shot and possibly expendable system is required. To generate the high-voltage pulse, it is necessary to attach a conditioning unit incorporating an opening switch (OS) to the FCG output. 
In cooperation with the Swedish Defence Research Agency (FOI), a power supply has been tested with a HPM source of the Vircator type (Fig. 8). The power generator for the system used a $70 \mathrm{~kJ} / 25 \mathrm{kV}$ capacitor bank and an exploding wire array to generate a $150 \mathrm{kV}$ voltage pulse in the primary circuit of a transformer. A pressurised $\mathrm{SF}_{6}$ spark gap in the secondary circuit sharpens the high-voltage output, so that pulses approaching $500 \mathrm{kV}$ and with a rise time well below 100 ns are generated on a $20 \Omega$ high-power resistor, with the peak power in excess of $10 \mathrm{GW}$. The overall arrangement is shown in Fig. 8 and details of the HV transformer are given in Fig. 9. Experimental results are also presented in Fig. 9 from final testing of the system, where a reflex triode Vircator replaces the $20 \Omega$ resistor. Measurements were made of the microwave emission using free-field sensors and the results obtained were similar to the microwave emission from the same Vircator even powered by a Marx generator at FOI.

\section{Facilities and expertise available at Loughborough}

The work ongoing at Loughborough would not be possible without the availability of considerable supporting facilities and expertise. A range of explosive and capacitor bank pulsed power sources ranging in output from $1 \mathrm{kA}$ to multi megampere currents are used in the laboratory and at remote firing sites. A wide range of opening and closing high-current, high-voltage switches is available, including rail gap switches rated at 1.2 MA. Numerous electromagnetic sensors and noise immune electro-optic and magneto-optic sensors have been developed in house. High-vacuum work can be undertaken, and the availability of high-speed cameras, mobile multi-flash x-ray equipment and high-performance oscilloscopes enables important events for be recorded in detail.

Well-proven and highly detailed numerical techniques have been developed that have enabled major contributions to be made to the two-dimensional modelling on components under transient conditions. Recently, the introduction of finite-element multi-physical modelling has led to an even greater understanding of the underlying physics of both destructive and nondestructive experimentation.

Loughborough also has several anechoic chambers that are used to measure and characterise antennas. A suite of commercial and in-house FDTD and TLM simulation software is available. 